\title{
SINTESIS BAHAN M-HEXAFERRITES DENGAN DOPING LOGAM Co MENGGUNAKAN FTIR
}

\author{
Susilawati $^{1}$, Khairunnisa ${ }^{2}$, Aris Doyan ${ }^{2}$ \\ ${ }^{1)}$ Program Studi Pendidika Fisika \\ 2) Program Studi Pendidika Fisika FKIP \\ Universitas Mataram \\ Mataram, Indonesia \\ Email: susilawatihambali@yahoo.co.id
}

\begin{abstract}
Has successfully carried out the study synthesis of materials M-heksaferit with doping metal Co using FTIR. The study was conducted to see the phase that forms on M-hexaferrites material by adding a transition metal element cobalt $(\mathrm{Co})$ with the mole fraction $\mathrm{x} 0,0.2,0.5,0.8,1.0$ done drying with $\mathrm{T} 80^{\circ} \mathrm{C}$ for 2 hours and calcined the T $400,600,800^{\circ} \mathrm{C}$ for 4 hours. Barium M-hexaferrites BaFe12O19 characterized using Fourier transform infrared spectroscopy (FTIR), the picture looks FTIR results for the mole fraction $\mathrm{x}$ $0.2,0.5,0.8$ and 1.0 located on T 8000C.
\end{abstract}

Keywords: Barium M-hexaferrites, cobalt, coprecipitation, FTIR.

\section{Pendahuluan}

Teknologi penyerapan gelombang elektromagnetik merupakan salah satu teknologi yang sedang pesat dikembangkan untuk mengontrol masalah yang ditimbulkan oleh elektromagnetik interference (EMI). Teknologi ini juga telah melahirkan sebuah material baru yaitu Radar Absorbing Material (RAM), salah satu aplikasi material ini yaitu pada bidang militer. Material ini bersifat meredam pantulan atau menyerap gelombang mikro sehingga benda yang dilapisi dengan RAM tidak terdeteksi oleh Radio Detection and Ranging (RADAR). Penyerap gelombang mikro terdiri dari dua komponen, penyerap dielektrik dan penyerap magnetik untuk itu perlu dikembangkan material yang dapat menyerap dielektrik dan menyerap magnetik (2).

Berbagai penelitian dalam rangka mengembangkan Radar Absorbing Material (RAM) semakin banyak dilakukan. Salah satunya adalah penelitian tentang La and Co substituted M-type barium ferrites processed by sol-gel combustion synthesis. (5).

Radar merupakan alat deteksi posisi benda dengan menggunakan microwave atau gelombang radio. Pada umumnya radar digunakan untuk angkatan udara maupun angkatan laut, untuk mendeteksi kapal maupun pesawat asing yang masuk ke wilayah suatu negara.

Mekanisme tak terdeteksinya suatu obyek oleh radar bersandarkan pada dua aspek: (1)
Obyek/pesawat dirancang dengan geometri bersudut radar absorbing structure (RAS), sehingga pantulan gelombang elektromagnetik tidak dapat ditangkap kembali oleh receiver, (2) Badan pesawat dilapisi oleh bahan penyerap gelombang radar yaitu radar absorbing materials (RAM) berupa Barium Mhexaferrites $\mathrm{BaFe}_{12} \mathrm{O}_{19}$. Pada penelitian ini telah dilakukan sintesis bahan M-hexaferrites dengan doping logam Co menggunakan FTIR sehingga terbentuk barium M-hexaferrites sebagai material magnetik yang dapat menyerap gelombang mikro.

Ada beberapa metode yang bisa digunakan dalam mensintesis barium hexaferrites diantaranya adalah metode sol gel, mekanika milling, kopresipitasi dan dapat juga didoping dengan logam transisi seperti $\mathrm{Zn}$, Co, Mn, Ni (9).

Mengacu pada penelitian sebelumnya barium $M$ hexaferrites memiliki beberapa tipe diantaranya tipe $\mathrm{M}$ memiliki senyawa kimia $\mathrm{BaFe}_{12} \mathrm{O}_{19}$, Tipe $\mathrm{Y}$ memiliki senyawa $\mathrm{Ba}_{2} \mathrm{Me}_{2} \mathrm{Fe}_{12} \mathrm{O}_{22}$ dan tipe $\mathrm{W}$ adalah $\mathrm{BaMe}_{2} \mathrm{Fe}_{16} \mathrm{O}_{27}$. Tipe $\mathrm{Z}$ memiliki senyawa $\mathrm{Ba}_{3} \mathrm{Me}_{2} \mathrm{Fe}_{24} \mathrm{O}_{41}$ sedangkan tipe $\mathrm{U}$ memiliki senyawa $\mathrm{Ba}_{4} \mathrm{Me}_{2} \mathrm{Fe}_{36} \mathrm{O}_{60}$. Simbol Me dalam struktur di atas merupakan logam transisi dua valensi seperti $\mathrm{Mn}^{2+} \mathrm{Ni}^{2+} \mathrm{Co}^{2+} \mathrm{Zn}^{2+}$ dan lain lain. Pada penelitian ini digunakan barium heksaferit dengan tipe $M$ karena bahan magnetik tipe $\mathrm{M}$ memiliki sifat magnetik uniaksial yang pada suhu kamar memiliki medan anisotropi pada kisaran 17,5 Koe. Berbagai penelitian menunjukkan bahwa medan annisotripi kristal dapat dilakukan dengan berbagai metoda antara melalui 
mekanisme nanomaterial maupun dengan substitusi parsial berbagai ion penyusunnya (8).

\section{TinjauAn Pustaka}

Barium hexa Ferrite merupakan keramik oksida komplek dengan rumus kimia $\mathrm{BaO} .6 \mathrm{Fe}_{2} \mathrm{O}_{3}$ atau $\mathrm{BaFe}_{12} \mathrm{O}_{19}$. Barium hexa Ferrite mempunyai kestabilan kimia yang bagus dan merupakan feromagnetik oksida dengan sifat dielektrik dan magnetik yang banyak digunakan pada aplikasi RF (Radio Frequency) dan microwave. Penggunaan BaM sebagai material magnet permanen dan perekam magnetik sangat diminati sehingga banyak penelitian dilakukan pada jenis material ini.

Berbagai sifat magnetik material dapat divariasi dengan substitusi pada kation yang berisi unsur besi $\mathrm{Fe}^{+2}$ dan $\mathrm{Fe}^{+3}$ dalam $\mathrm{BaFe}_{12} \mathrm{O}_{19}$. Divalen logam transisi seperti $\mathrm{Ni}, \mathrm{Co}, \mathrm{Mn}, \mathrm{Cr}$, Ti sering digunakan karena memiliki persamaan jari-jari ionik dan konfigurasi elektron. Sifat kelistrikan dan kemagnetan dari substitusi $\mathrm{BaM}$ sangat bergantung pada kondisi sintesisnya karena disebabkan oleh ketidaksebandingan distribusi muatan pada proses substitusi multivalen kationnya (8)

Berdasarkan rumus kimia dan struktur kristalnya, barium heksaferit dikelompokkan menjadi 6 tipe yaitu $\mathrm{M} \quad\left(\mathrm{BaFe}_{12} \mathrm{O}_{19}\right), \quad \mathrm{Y} \quad\left(\mathrm{BaMe}_{2} \mathrm{Fe}_{12} \mathrm{O}_{22}\right), \quad \mathrm{W}$ $\left(\mathrm{BaMe}_{2} \mathrm{Fe}_{16} \mathrm{O}_{27}\right), \quad \mathrm{Z} \quad\left(\mathrm{Ba}_{3} \mathrm{Me}_{2} \mathrm{Fe}_{24} \mathrm{O}_{41}\right), \quad \mathrm{X}$ $\left(\mathrm{Ba}_{2} \mathrm{Me}_{2} \mathrm{Fe}_{28} \mathrm{O}_{46}\right)$ dan $\mathrm{U}\left(\mathrm{Ba}_{4} \mathrm{Me}_{2} \mathrm{Fe}_{36} \mathrm{O}_{60}\right)$. M, Y, W, $\mathrm{Z}, \mathrm{X}$, dan $\mathrm{U}$ menyatakan tipe dari barium heksaferit yang ditentukan oleh jumlah kandungan ion besi dan oksigen dalam senyawa. Sedangkan M menyatakan suatu variabel yang bisa diganti dengan ion $\mathrm{Zn}, \mathrm{Ti}$, $\mathrm{Co}, \mathrm{Ga}, \mathrm{Al}$, serta kation logam lainnya yang ukurannya hampir sama sesuai dengan sifat yang ingin dimunculkan (1).

\section{Metode Penelitian}

Barium hexa Ferrite merupakan keramik oksida komplek dengan rumus kimia $\mathrm{BaO} .6 \mathrm{Fe}_{2} \mathrm{O}_{3}$ atau $\mathrm{BaFe}_{12} \mathrm{O}_{19}$. Barium hexa Ferrite mempunyai kestabilan kimia yang bagus dan merupakan feromagnetik oksida dengan sifat dielektrik dan magnetik yang banyak digunakan pada aplikasi RF (Radio Frequency) dan microwave. Penggunaan BaM sebagai material magnet permanen dan perekam magnetik sangat diminati sehingga banyak penelitian dilakukan pada jenis material ini.

Berbagai sifat magnetik material dapat divariasi dengan substitusi pada kation yang berisi unsur besi $\mathrm{Fe}^{+2}$ dan $\mathrm{Fe}^{+3}$ dalam $\mathrm{BaFe}_{12} \mathrm{O}_{19}$. Divalen logam transisi seperti $\mathrm{Ni}, \mathrm{Co}, \mathrm{Mn}, \mathrm{Cr}$, Ti sering digunakan karena memiliki persamaan jari-jari ionik dan konfigurasi elektron. Sifat kelistrikan dan kemagnetan dari substitusi BaM sangat bergantung pada kondisi sintesisnya karena disebabkan oleh ketidaksebandingan distribusi muatan pada proses substitusi multivalen kationnya (8)

Berdasarkan rumus kimia dan struktur kristalnya, barium heksaferit dikelompokkan menjadi 6 tipe yaitu $\mathrm{M} \quad\left(\mathrm{BaFe}_{12} \mathrm{O}_{19}\right), \quad \mathrm{Y} \quad\left(\mathrm{BaMe}_{2} \mathrm{Fe}_{12} \mathrm{O}_{22}\right), \quad$ W $\left(\mathrm{BaMe}_{2} \mathrm{Fe}_{16} \mathrm{O}_{27}\right), \quad \mathrm{Z} \quad\left(\mathrm{Ba}_{3} \mathrm{Me}_{2} \mathrm{Fe}_{24} \mathrm{O}_{41}\right), \quad \mathrm{X}$ $\left(\mathrm{Ba}_{2} \mathrm{Me}_{2} \mathrm{Fe}_{28} \mathrm{O}_{46}\right)$ dan $\mathrm{U}\left(\mathrm{Ba}_{4} \mathrm{Me}_{2} \mathrm{Fe}_{36} \mathrm{O}_{60}\right)$. M, Y, W, $\mathrm{Z}, \mathrm{X}$, dan $\mathrm{U}$ menyatakan tipe dari barium heksaferit yang ditentukan oleh jumlah kandungan ion besi dan oksigen dalam senyawa. Sedangkan M menyatakan suatu variabel yang bisa diganti dengan ion $\mathrm{Zn}, \mathrm{Ti}$, $\mathrm{Co}, \mathrm{Ga}, \mathrm{Al}$, serta kation logam lainnya yang ukurannya hampir sama sesuai dengan sifat yang ingin dimunculkan (1).

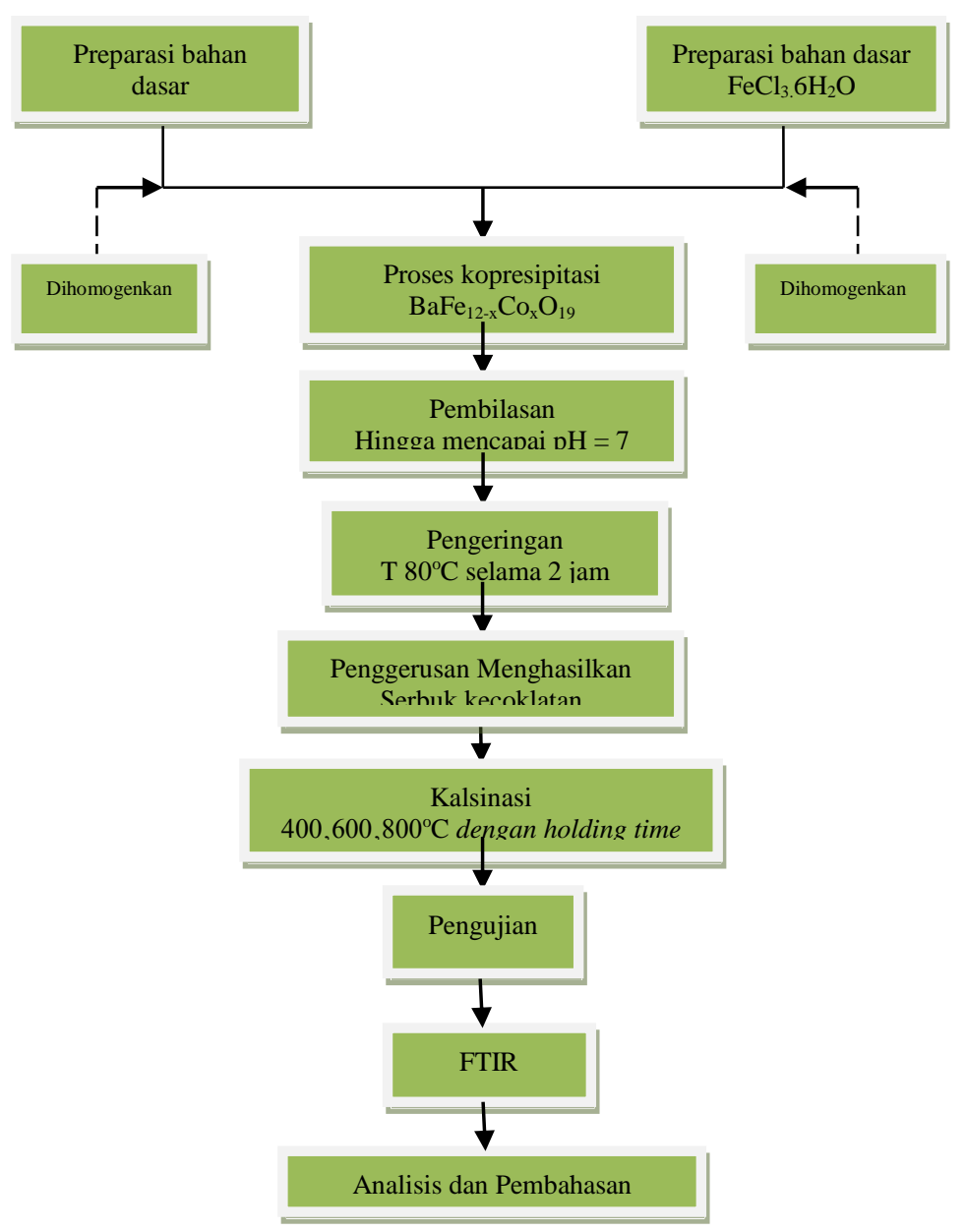

\section{Hasil dan Pembahasan}

Hasil penelitian didapatkan berupa serbuk dari barium M-hexaferrites berwarna kecoklatan terlihat pula perubahan warna pada serbuk tersebut karena adanya perbedaan banyaknya doping Co dan suhu 
yang digunakan pada sintering. Hal ini dapat terlihan pada Gambar 2.

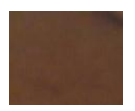

b
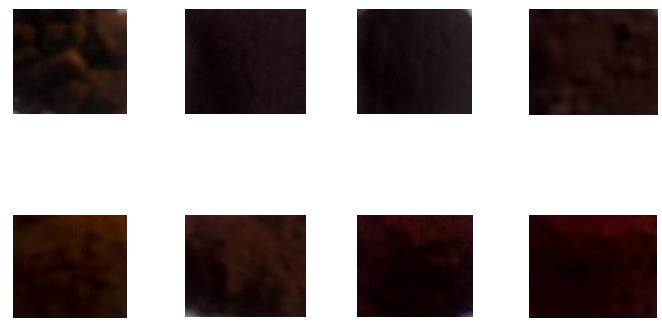

d
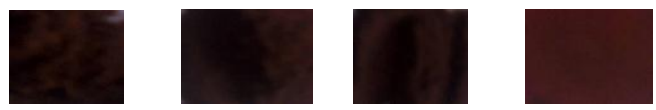

Gambar 2. $\mathrm{BaFe}_{12} \mathrm{CoO}_{19}$ (a) $\mathrm{Cox}=0,2$ (b) $\mathrm{Cox}=0,5$ (c) $\mathrm{Cox}=0,8$ dan (d) $\mathrm{Cox}=1$

\section{Fourier Transform Infra Red Spectroscopy FTIR}

Tujuan dari pengujian menggunakan FTIR adalah untuk menginterpretasikan terjadinya proses substitusi doping logam Co terhadap struktur ikatan kristal dan melihat senyawa yang terbentuk dalam sampel. Dari hasil pengujian terlihat bahwa senyawa selain $\mathrm{BaM}$ dalam bahan sudah hilang terlihat pada grafik dari hasil pengujian. Pengujian di mulai dari $\mathrm{x}$ $=0,0,2$ 0,5 0,8 dan 1,0 dengan suhu masing masing $80,400,600$ dan $800^{\circ} \mathrm{C}$.

Sebelum dilakukan pengujian FTIR terlebih dahulu serbuk dicampur dengan $\mathrm{KBr}$ untuk dijadikan pelet tujuan dari pemberian $\mathrm{KBr}$ yaitu sebagai background, setelah bahan sudah berbentuk pelet bahan dimasukan kedalam FTIR untuk dilakukan pengujian. Umumnya spektrofotometer IR digunakan untuk mengidentifikasi gugus fungsi pada suatu senyawa, terutama senyawa organik, akan tetapi ada beberapa peneliti yang menggunakan FTIR dalam menganalisis barium $M$-hexaferrites seperti $(5 ; 7 ; 3)$ dimana tujuannya adalah untuk melihat terjadinya subtitusi Fe setelah di doping Co pada BaM. Hasi pengujian dapat dilihat pada Gambar 3 sampai Gambar 7 dibawah ini.

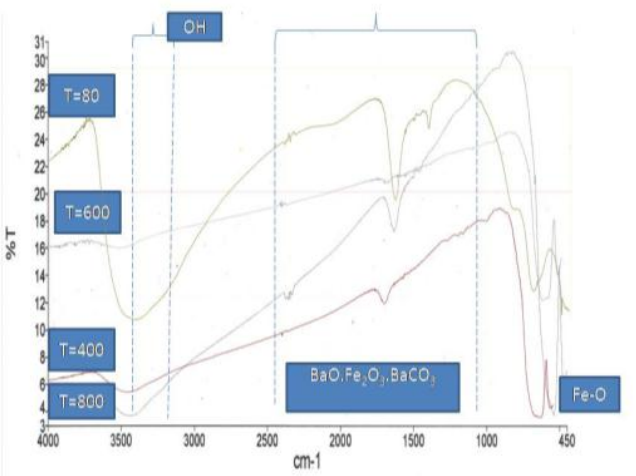

Gambar 3. Hasil pengujian tampa doping menggunakan FTIR dengan suhu 80, 400, 600 dan $800^{\circ} \mathrm{C}$.

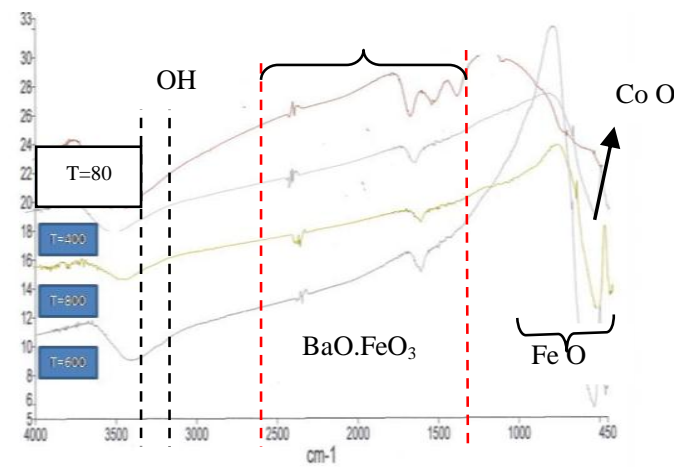

Gambar 4. Hasil pengujian menggunakan FTIR dengan $\mathrm{x}=0,2$ dengan suhu $80,400,600$ dan $800^{\circ} \mathrm{C}$.

Gambar 4. Merupakan hasil pengujian FTIR pada $\mathrm{x}=0,2$ dimana pada gambar tersebut meningkatnya temperatur kalsinasi menyebabkan berkurangnya senyawa pengotor puncak yang terbentuk pada $\mathrm{x}=0,2$ kalsinasi yang baik berada pada suhu $600^{\circ} \mathrm{C}$.

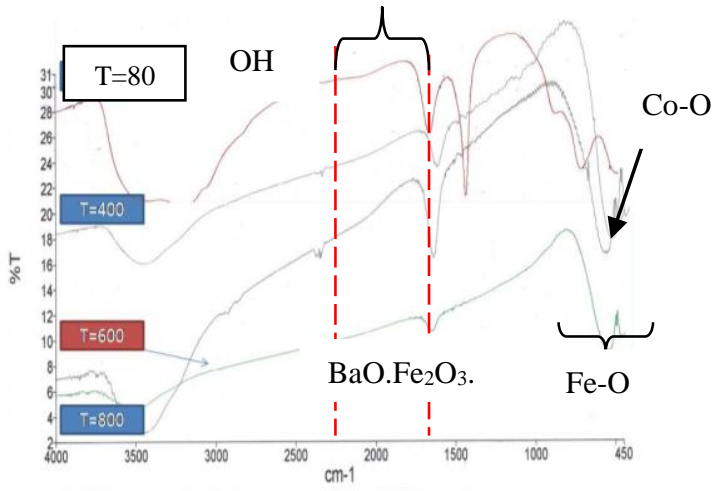

Gambar 5. Hasil pengujian menggunakan FTIR dengan $\mathrm{x}=0,5$ dengan suhu $80,400,600$ dan $800^{\circ} \mathrm{C}$.

Gambar 5. Merupakan hasil pengujian FTIR pada $\mathrm{x}=0,5$ dimana pada gambar tersebut meningkatnya temperatur kalsinasi menyebabkan berkurangnya senyawa lain seperti $\mathrm{OH}, \mathrm{NH}_{4} \mathrm{OH}$ kalsinasi yang baik berada pada suhu $800^{\circ} \mathrm{C}$. 


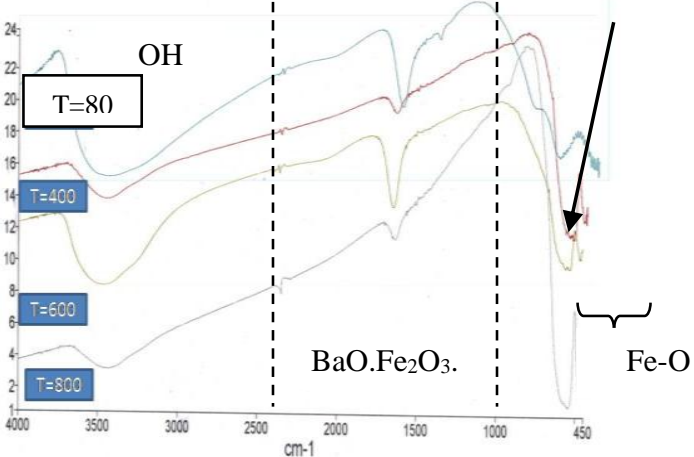

Gambar 6. Hasil pengujian menggunakan FTIR dengan $\mathrm{x}=0,8$ dengan suhu $80,400,600$ dan $800^{\circ} \mathrm{C}$.

Gambar 6. Merupakan hasil pengujian FTIR pada $\mathrm{x}=0,8$ dimana pada gambar ini meningkatnya temperatur kalsinasi menyebabkan berkurangnya senyawa selain $\mathrm{BaM}$ dari puncak dapat dilihat pada $\mathrm{x}=0,8$ kalsinasi yang baik berada pada suhu paling tinggi yaitu $800^{\circ} \mathrm{C}$. Dari gambar terlihat jelas perbedaan antara sampel yang dipanaskan pada $\mathrm{T} 80$, 400,600 dan $800^{\circ} \mathrm{C}$.

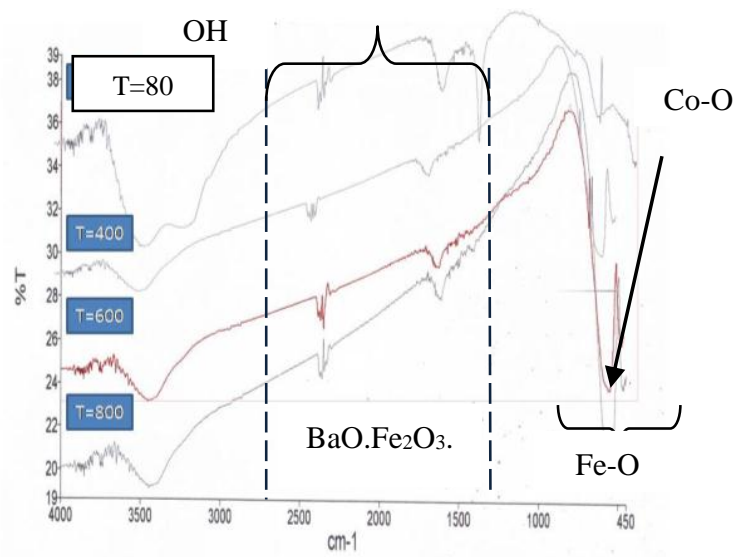

Gambar 7. Hasil pengujian menggunakan FTIR dengan $\mathrm{x}=1,0$ dengan suhu $80,400,600$ dan 800 ${ }^{\circ} \mathrm{C}$.

Gambar 3 sampai Gambar 7 memeperlihatkan dengan meningkatnya suhu kalsinasi senyawa senyawa yang tidak diinginkan seperti $\mathrm{OH}, \mathrm{NH}_{4} \mathrm{OH}$, $\mathrm{HCl}$ dan lainya menguap pada suhu tinggi. Pada Gambar 4 sampai Gambar 7 terlihat puncak yang terbentuk pada bilangan gelombang yang bervariasi. Jumlah puncak yang muncul pada rentang bilangan gelombang 1000-1700 $\mathrm{cm}^{-1}$ hampir sama pada masing masing gambar. Menurut hasil penelitian (5) rentang bilangan gelombang $1623 \mathrm{~cm}^{-1}$ merupakan $\mathrm{C}-\mathrm{H}$ dan bilangan gelombang $600-450 \mathrm{~cm}^{-1}$ merupakan karaktreristik dari ikatan $\mathrm{Fe}_{2} \mathrm{O}_{3}$ dan $\mathrm{BaO}$ dimana ikatan-ikatan tersebut merupakan ikatan penyusun barium M-hexaferrites, pada rentang bilangan gelombang $3500 \mathrm{~cm}^{-1}$ adalah karakteristik dari ikatan $\mathrm{O}-\mathrm{H}$, puncak-puncak yang berada pada rentang bilangan gelombang 800-1650 $\mathrm{cm}^{-1}$ menunjukkan puncak karekteristik penyerapan getaran dari kelompok karbonat $\mathrm{CO}_{3}{ }^{2-}$ hal ini senada dengan hasil penelitian (3). Sedangkan rentang gelombang 450-650 $\mathrm{cm}^{-1}$ adalah karakteristik dari ikatan $\mathrm{Fe}-\mathrm{O}$ sesuai dengan pernyataan (5) bahwa karakteristik getaran pada $450 \mathrm{~cm}^{-1}$ dan $570 \mathrm{~cm}^{-1}$ adalah karakteristik pada ikatan Fe-O yang merupakan karekteristik dari barium ferit. Ditinjau dari beberapa referensi dapat disimpulkan bahwa sudah membentuk senyawa Barium M-hexaferrites.

\section{Penutup}

Hasil pengujian dapat disimpulkan bahwa meningkatnya suhu kalsinasi menyebabkan hilangnya senyawa lain selain $\mathrm{BaM}$ dan terjadi proses kristalisasi yang menyebabkan sejumlah ikatan terlepas dan hilang sehingga terjadi reduksi masa pada suhu 600 dan $800^{\circ} \mathrm{C}$ dan pembentukan barium M-hexaferrites yang terbaik yaitu pada $\mathrm{x}=0,2$ dengan suhu $80^{\circ} \mathrm{C}$ dan $\mathrm{x}=0,8$ dan 1,0 pada kalsinasi $800^{\circ} \mathrm{C}$ dan sudah membentuk barium M-hexaferrites pada suhu $800^{\circ} \mathrm{C}$.

\section{UCAPAN TERIMA KASIH}

Kepada semua pihak yang telah membantu sehingga terwujudnya artikel ini dan penelitian ini telah di danai oleh hibah penelitian unggulan Perguruan Tinggi (PUPT) Menristek Dikti tahun anggaran 2015. Ucapan terima kasih juga kami sampaikan kepada Laboraturium Analitik Unram serta pihak lain yang telah memberikan masukan dan tinjauan kritis guna penyempurnaan tulisan ini.

\section{REFERENSI}

[1] Arasi S, Astuti. (2012). "Sintesis Nanokomposit $\mathrm{Pani} / \mathrm{TiO}_{2} / \mathrm{Karbon}$ sebagai menyerap gelombang mikro". Jurnal fisika Unand Vol.1 No.1

[2] Chauhan C,dkk. (2013). "Structural properties of cobalt Substituted barium hexaferrite Nanoparticles prepared by a thermal Treatment method'. Nanosystems: Physics, Chemistry, Mathematics.

[3] Li W, Qiao X, Li M, Liu T dan Peng H.X. (2013). "La and Co Substituted M-type Barium Ferrites Processed by Sol Gel Combustion Synthesis". Materials Research Bulletin 48.

[4] Mitrayana, Gelombang Mikro. (Online): Diakses tanggal 30 Desember 2014. 
[5] Ompakesh S, Praveen A dan Naik P.S. (2012). "Synthesis Characterization and DC Conductivity of Barium Hexaferrite". International Journal of Scientific \& Engineering Research Volume 3.Issue 5.

[6] Priyono, Windu Ganar Prasongko. (2013). "Pembuatan Material Magnetik Komposit $\mathrm{BaFe}_{9} \mathrm{Mn}_{0,75} \mathrm{Co}_{0,75} \mathrm{Ti}_{1,5} \mathrm{O}_{19}$ / Elastomer untuk Aplikasi Penyerap Gelombang Elektromagnetik". Jurnal sains dan matematika Vol.21

[7] Susilawati dan Doyan A. (2013). "Sintesis dan Studi Pendahuluan Struktur Bahan MHeksaferrites untuk Aplikasi Anti Radar", Proseding Seminar Nasional Penelitian, Pembelajaran Sains dan Implementasi Kurikulum 2013. Program Studi Magister Pendidikan IPA Program Pascasarjana Universitas Matarm. 7 Desember 2014. 